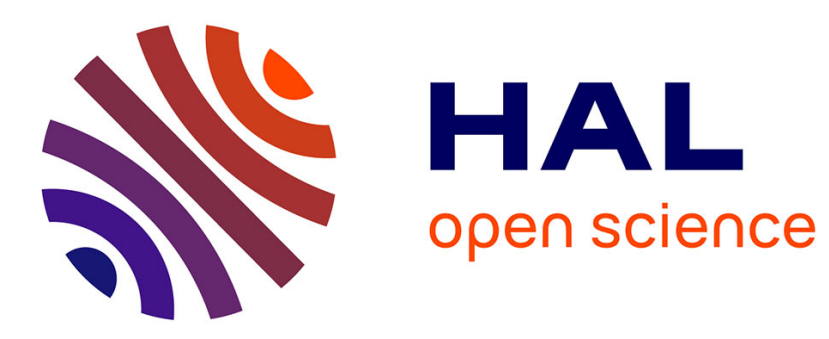

\title{
Meta- and hybrid-CNTs: A clue for the future development of carbon nanotubes
}

Marc Monthioux, Emmanuel Flahaut

\section{To cite this version:}

Marc Monthioux, Emmanuel Flahaut. Meta- and hybrid-CNTs: A clue for the future development of carbon nanotubes. Materials Science and Engineering: C, 2007, vol. 27, pp. 1096-1101. 10.1016/j.msec.2006.07.032 . hal-00807916

\section{HAL Id: hal-00807916 https://hal.science/hal-00807916}

Submitted on 4 Apr 2013

HAL is a multi-disciplinary open access archive for the deposit and dissemination of scientific research documents, whether they are published or not. The documents may come from teaching and research institutions in France or abroad, or from public or private research centers.
L'archive ouverte pluridisciplinaire HAL, est destinée au dépôt et à la diffusion de documents scientifiques de niveau recherche, publiés ou non, émanant des établissements d'enseignement et de recherche français ou étrangers, des laboratoires publics ou privés. 


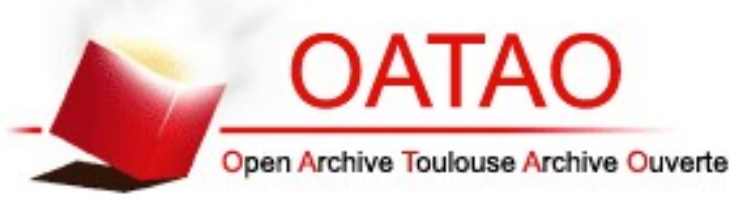

\section{Open Archive Toulouse Archive Ouverte (OATAO)}

OATAO is an open access repository that collects the work of Toulouse researchers and makes it freely available over the web where possible.

This is an author-deposited version published in: http://oatao.univ-toulouse.fr/ Eprints ID : 2467

To link to this article :

URL : http://dx.doi.org/10.1016/j.msec.2006.07.032

To cite this version : Monthioux, Marc and Flahaut, Emmanuel ( 2007) Meta- and hybrid-CNTs: A clue for the future development of carbon nanotubes. Materials Science and Engineering C, vol. 27 ( ${ }^{\circ} 5$ - 8). pp. 1096-1101. ISSN 0928-4931

Any correspondence concerning this service should be sent to the repository administrator:staff-oatao@inp-toulouse.fr 


\title{
Meta- and hybrid-CNTs: A clue for the future development of carbon nanotubes
}

\author{
M. Monthioux ${ }^{a, *}$, E. Flahaut ${ }^{b}$ \\ ${ }^{a}$ Centre d'élaboration des Matériaux et d'Etudes Structurales (CEMES), UPR-8011 CNRS, BP 94347, F-31055 Toulouse cedex 04, France \\ ${ }^{\mathrm{b}}$ Centre Interuniversitaire de Recherche et d'ingénierie des Matériaux (CIRIMAT), UMR-5085 CNRS, Bât. 2R1, \\ 118 Route de Narbonne, F-31062 Toulouse, France
}

\begin{abstract}
A new generation of carbon nanotubes (CNTs), which may be named "meta-nanotubes", is more and more the focus of the research worldwide. They result from the transformation of "regular" CNTs by various ways such as functionalisation, doping, substitution, etc. The new nanomaterials thereby created are likely to exhibit new behaviors, specifically regarding properties that pristine CNTs do not possess (reactivity, solubility, magnetism...). The paper includes the description of the various routes to synthesize hybrid CNTs and their related advantages and limitations, while providing examples of the resulting materials from both literature and author's team work. Hybrid SWNTs (abbreviated as X@SWNTs) are one example of meta-nanotubes, and consist in SWNTs whose the hollow core is fully or partially filled with foreign atoms, molecules, or compounds. The inserted material may then exhibit a peculiar behavior with respect to the macroscopic state, for several non-exclusive reasons: 1D-dimension preventing electron scattering and enhancing the role of surface atoms, protection from surface adsorption of disturbing molecules by the carbon sheath, anisotropic lattice distortion or creation of new structures due to imposed dimensions, interactions/electron coupling with the surrounding carbon lattice. A wide field is thus open, possibly even wider than for pristine SWNTs.
\end{abstract}

Keywords: Sublimation; Insertion; Solution; Filling; Carbon nanotube; Properties

\section{Introduction to meta-nanotubes}

Multi-wall carbon nanotubes (MWNTs) have been known for more than 50 years [1,2], and single-wall carbon nanotubes (SWNTs) for 13 years $[3,4]$. The various conditions for their synthesis are now well defined, and most of their properties well predicted. Research works are now mainly dealing with the applications of CNTs, i.e., with the actual incorporation of CNTs in devices. Unfortunately, the specificities of CNTs often make the latter difficult, e.g., due to poor reactivity, low dispersability, intrinsic insolubility, etc. Also, though already doted with unique properties, the latter are worth being enhanced (e.g., transport, magnetism, etc.). A new generation of CNTs, that may be named "meta-nanotubes" is therefore now the focus of material scientists, which basically results from the chemical trans-

\footnotetext{
* Corresponding author.

E-mail address: marc.monthioux@cemes.fr (M. Monthioux).
}

formation of pristine CNTs. Five main categories of metananotubes may be defined:

- Functionalized nanotubes, are CNTs at the surface of which various individual chemical functions are grafted (i.e., the foreign materials does not form a phase by itself).

- Coated nanotubes, are CNTs at the surface of which a foreign material is deliberately fixed, either as a continuous coating (e.g., polymer), or as a discontinuous coating (e.g., nanoparticles, biomolecules).

- Heterogeneous nanotubes, are CNTs whose carbon atoms from the hexagonal graphene lattice are partially or even totally substituted with hetero-atoms (typically nitrogen and/ or boron).

- Doped nanotubes, are carbon nanotubes which have been intimately associated with electron donor or acceptor elements such as $\mathrm{Br}_{2}, \mathrm{~K}, \mathrm{Rb}$, etc. (or compounds, more scarcely) with an association mechanism that closely relates to that of intercalation compounds in graphite. 
- Hybrid nanotubes, are CNTs which the inner cavity has been filled with foreign atoms, molecules, or compounds. They are probably the most versatile of the meta-nanotubes described here, and thereby are likely the ones which open the wider research field, both regarding scientific and technological aspects. The current paper is dedicated to them, as an abbreviated version of a more extended paper published elsewhere [5].

\section{Hybrid carbon nanotubes}

\subsection{Motivation for filling nanotubes}

Both MWNTs and SWNTs are able to be transformed into hybrid CNTs (noted X@CNT, where X is generally the chemical formulae of the filling material). However, because of the smaller diameters involved in SWNTs as opposed to MWNTs, more specific properties are expected for X@SWNT due to the truly 1D-morphology enforced for the filling materials. The inserted material may then exhibit a peculiar behavior (e.g., quantum wire) with respect to the macroscopic state, for several non-exclusive reasons: 1D-dimension preventing electron scattering and enhancing the role of surface atoms, protection from surface adsorption of disturbing molecules by the carbon sheath, anisotropic lattice distortion or creation of new structures due to imposed dimensions, interactions/electron coupling with the surrounding carbon lattice.

Evidence for the ability of SWNTs to be filled with foreign materials was reported for the first time in 1998, one from the incidental filling of fullerenes thereby forming so-called nanopeapods [6], the other from the first attempt to deliberately fill SWNTs, with $\mathrm{RuCl}_{3}$ subsequently reduced in Ru metal [7]. Until few years ago, making a review of all the works published in the field worldwide was still possible [8]. Since then, the interest regarding the synthesis and properties of such materials (e.g., peapods) has increased in such a proportion that the latter has become difficult. The main attempt is to tentatively modify the electronic structure of the subsequent hybrid nanotubes in order to obtain peculiar electronic behaviors with respect to pristine SWNTs via band gap modulations, for instance systematic metallic behavior, superconductivity, magnetic behavior, etc.

\subsection{Filling materials}

Any kind of materials (i.e., atoms, molecules, and compounds) has now been experimentally inserted in SWNT cavity to form hybrid SWNTs. Table 1 provides a tentatively exhaustive list of the materials whose successful insertion has already been reported in literature. References are provided for the pioneering works in each category only, the other related references may be found in [5]. Only actual filling was considered, i.e., the listing does not include materials whose insertion was demonstrated via modeling only. Works dealing with filling SWNTs with permanent gases (e.g., $\mathrm{H}_{2}$ ) are not included either, since the actual insertion of the latter within the SWNT cavity was hardly demonstrated and is still a debated matter. Elements between parentheses were inserted as salts first then chemically reduced, generally via thermal treatments under hydrogen-rich atmosphere. Most of the halide-based hybrid nanotubes listed are among the works of the University of Oxford, which is the most active laboratory in the field. The large variety of halides that have been inserted already as opposed to the few oxides reveals the difficulty to find oxides that fulfill constrains related to the filling methods, for which filling materials have to melt at a reasonable temperature (typically, below $\sim 1000-1200^{\circ} \mathrm{C}$ ) or to be soluble, when they are not able to sublime or vaporize. Beyond this temperature threshold, the behavior of nanotubes in contact with molten materials may differ from a filling material to another and requires dedicated investigations so that the effect on the nanotube structure is controlled.

\subsection{Synthesis strategy}

Filling materials can be inserted as a solid, a liquid, or a vapor, either following in-situ or ex-situ routes. Examples for successful synthesis of hybrid SWNTs via in-situ routes (i.e., SWNTs are filled while they formed) are very seldom, due to the intrinsic constrains associated with the main methods for SWNT synthesis (catalyst-enhanced chemical vapor deposition, and electric arc plasma). Ex-situ routes are therefore extensively used. The latter may be single-step, which is preferred for sake of simplicity and cost. When the latter is not possible, up to three steps may be necessary, typically accounting for a first step dedicated to the opening of the nanotubes and a final step dedicated to the subsequent transformation of the inserted material into the desired material, in addition to the main filling step. Using intermediate material for filling may actually be necessary when the desired material does not have the appropriate physical constants (e.g., vaporization temperature, sublimation temperature, surface tension at molten state, ...). Fig. 1 gathers the various steps and ways that may be used for achieving the insertion of the various materials listed in Table 1 in SWNTs. Most of the paths are also valid for filling MWNTs. Fig. 2 provides examples of hybrid nanotubes obtained following various routes.

SWNTs usually require to be opened prior to filling, unless naturally open nanotubes are used (e.g., from templating). Opening the nanotubes is achieved by gas phase (air, oxygen) or liquid phase (e.g., nitric acid) oxidation. As evidenced by transmission electron microscopy imaging sequences [21], such an oxidation treatment creates side openings in SWNT walls in addition to openings at the tube tips, in lieu of defective sites whose occurrence is in the range of one structural defect (StoneWales defect, typically) every five nanometers along the tube wall, as discussed in [8].

Only one gas route is available (left in Fig. 1), which consists in putting in contact both the previously opened nanotubes (MWNTs or SWNTs) and the vapor of the material to insert in them, for instance in a quartz vessel which should be evacuated prior to be sealed then heated up at the vaporization (or sublimation) temperature of the filling material. This is the way peapods were - and still are, usually - prepared [21]. This route is interesting because of its simplicity (two steps only, opening and filling, considering that using intermediate materials with 
Table 1

Listing of the various kind of materials reported in literature as having been successfully inserted in SWNTs

\begin{tabular}{|c|c|c|}
\hline $\begin{array}{l}\text { Nature of } \\
\text { filling materials }\end{array}$ & $\begin{array}{l}\text { Morphology } \\
\text { (as encapsulated in SWNTs) }\end{array}$ & Chemical formulae \\
\hline Atoms & $\begin{array}{l}\text { Single atom chains, } \\
\text { or isolated }\end{array}$ & $\mathrm{I}[9], \mathrm{Cs}$ \\
\hline \multirow[t]{5}{*}{ Molecules } & $\begin{array}{l}\text { Mainly as single } \\
\text { molecule chains }\end{array}$ & Fullerenes: $\mathrm{C}_{60}[6], \mathrm{C}_{70}, \mathrm{C}_{78}, \mathrm{C}_{80}, \mathrm{C}_{84}, \mathrm{C}_{90}$ \\
\hline & & $\begin{array}{l}\text { Endohedral fullerenes: } \mathrm{La}_{2} @ \mathrm{C}_{80}[10], \mathrm{Gd} @ \mathrm{C}_{82}[11,12], \mathrm{N} @ \mathrm{C}_{60}, \mathrm{Sc}_{3} \mathrm{~N} @ \mathrm{C}_{80}, \mathrm{Er}_{x} \mathrm{Sc}_{3-x} \mathrm{~N} @ \mathrm{C}_{80}, \mathrm{La} @ \mathrm{C}_{82}, \\
\mathrm{La}_{2} @ \mathrm{C}_{82}, \mathrm{Sm} @ \mathrm{C}_{82}, \mathrm{Dy} @ \mathrm{C}_{82}, \mathrm{Tm} @ \mathrm{C}_{82}, \mathrm{Ca} @ \mathrm{C}_{82}, \mathrm{Sc}_{2} @ \mathrm{C}_{84}, \mathrm{Gd}_{2} @ \mathrm{C}_{92}\end{array}$ \\
\hline & & doped fullerenes: fullerenes combined with elements (e.g., $\mathrm{K}$ ) or compounds (e.g., $\mathrm{FeCl}_{3}$ ) [13] \\
\hline & & $\begin{array}{l}\text { Functionalized fullerenes: } \mathrm{C}_{60} \text { grafted with: dicarboxylic acid diethyl ester }\left(\mathrm{C}_{61}(\mathrm{COOet})_{2} @ \mathrm{SWNT}\right)[14] \text {, } \\
4 \text { (pyrrolidin-1-yl)phenol }\end{array}$ \\
\hline & & Organic molecules: ferrocene [15], nickelocene, carborane, fulvalenes, $\mathrm{Zn}$-diphenyl-porphyrin, $\mathrm{H}_{2} \mathrm{O}$. \\
\hline \multirow[t]{2}{*}{ Elements } & $\begin{array}{l}\text { Nanowires, } 1 \mathrm{D} \text {-crystals, } \\
\text { elongated nanoparticles }\end{array}$ & Direct: $\mathrm{Bi}[16], \mathrm{Se}$ \\
\hline & & From salt reduction: $\mathrm{Ru}[7], \mathrm{Bi}, \mathrm{Ag}, \mathrm{Au}, \mathrm{Pt}, \mathrm{Pd}$ \\
\hline \multirow[t]{2}{*}{ Compounds } & $\begin{array}{l}\text { Nanowires, } 1 \mathrm{D} \text {-crystals, } \\
\text { elongated nanoparticles }\end{array}$ & $\begin{array}{l}\text { Halides: } \mathrm{RuCl}_{3}[7], \mathrm{NaCl}, \mathrm{TiCl}, \mathrm{CdCl}_{2}, \mathrm{FeCl}_{2}, \mathrm{CoCl}_{2}, \mathrm{TbCl}_{3}, \mathrm{Al}_{2} \mathrm{Cl}_{6}, \mathrm{HoCl}_{3}, \mathrm{GdCl}_{3}, \mathrm{Ln}(\mathrm{La} \text { to } \mathrm{Lu}) \mathrm{Cl}_{3}, \mathrm{HfCl}_{4}, \mathrm{ThCl}_{4} \text {, } \\
\mathrm{ZrCl}_{4}, \mathrm{ThCl}_{6}, \mathrm{WCl}_{6},(\mathrm{KCl})_{x}(\mathrm{UCl} 4)_{y}, \mathrm{AgCl}_{x} \mathrm{Br}_{y} \mathrm{I}_{z}, \mathrm{Cs}(\mathrm{Cl} / \mathrm{Br} / \mathrm{I}),(\mathrm{K} / \mathrm{Li} / \mathrm{Na} / \mathrm{Rb} / \mathrm{Ag}) \mathrm{I}, \mathrm{CdI}_{2}, \mathrm{CoI}_{2}, \mathrm{SrI}_{2}, \mathrm{BaI}_{2}, \mathrm{PbI}_{2}, \mathrm{HgI}_{2} \text {, } \\
\mathrm{TeI}_{4}, \mathrm{SnI}_{4}, \mathrm{MoCl}_{5}\end{array}$ \\
\hline & & Oxides: $\mathrm{CrO}_{3}$ [17], $\mathrm{Sb}_{2} \mathrm{O}_{3}$ [18], $\mathrm{PbO}, \mathrm{Re}_{x} \mathrm{O}_{y}$ \\
\hline
\end{tabular}

this method has not been common in literature so far, yet possible), and first of all because of its potentiality for high filling rate due to the fact that only the desired molecules enter the SWNT cavity, free of any solvent molecules.

Besides the gas phase route, most of the other methods are liquid phase methods, meaning that the liquid involved has to exhibit a surface tension value below the threshold of $100-200 \mathrm{mN} /$ $m$ identified by Dujardin et al. [22], and hopefully a viscosity low enough for allowing reasonable filling kinetics. When solvents are involved, the surface tension is not a problem since usual solvents exhibit surface tension value below $80 \mathrm{mN} / \mathrm{m}$.

The suspension method is dedicated to the filling with nanoparticles, of which examples involving SWNTs are not available yet for the obvious reason that preparing nanoparticles

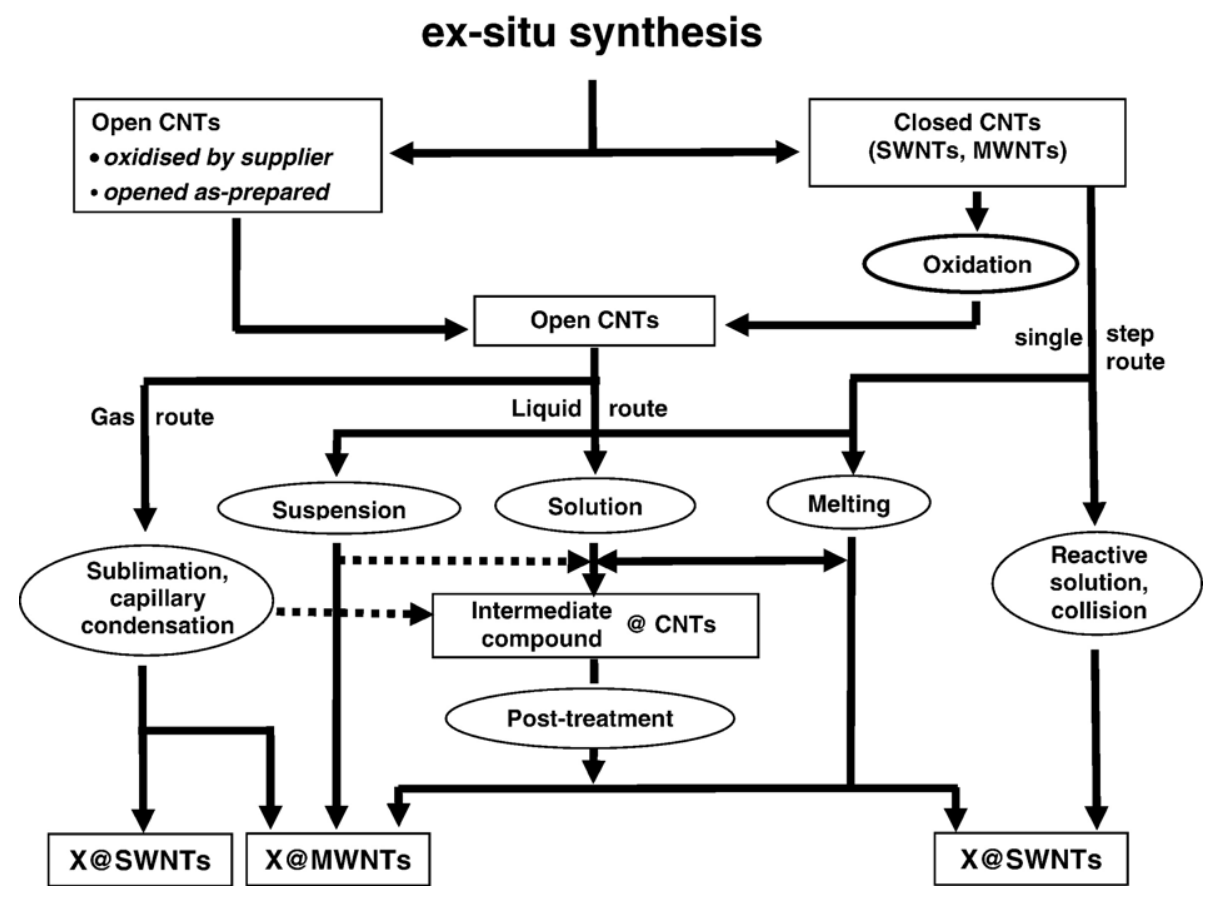

Fig. 1. The various ways and steps able to be used for ex-situ synthesis of hybrid SWNTs and MWNTs. Rectangles are for materials, ovals are for treatments. Solid lines are preferred paths. From [5]. 


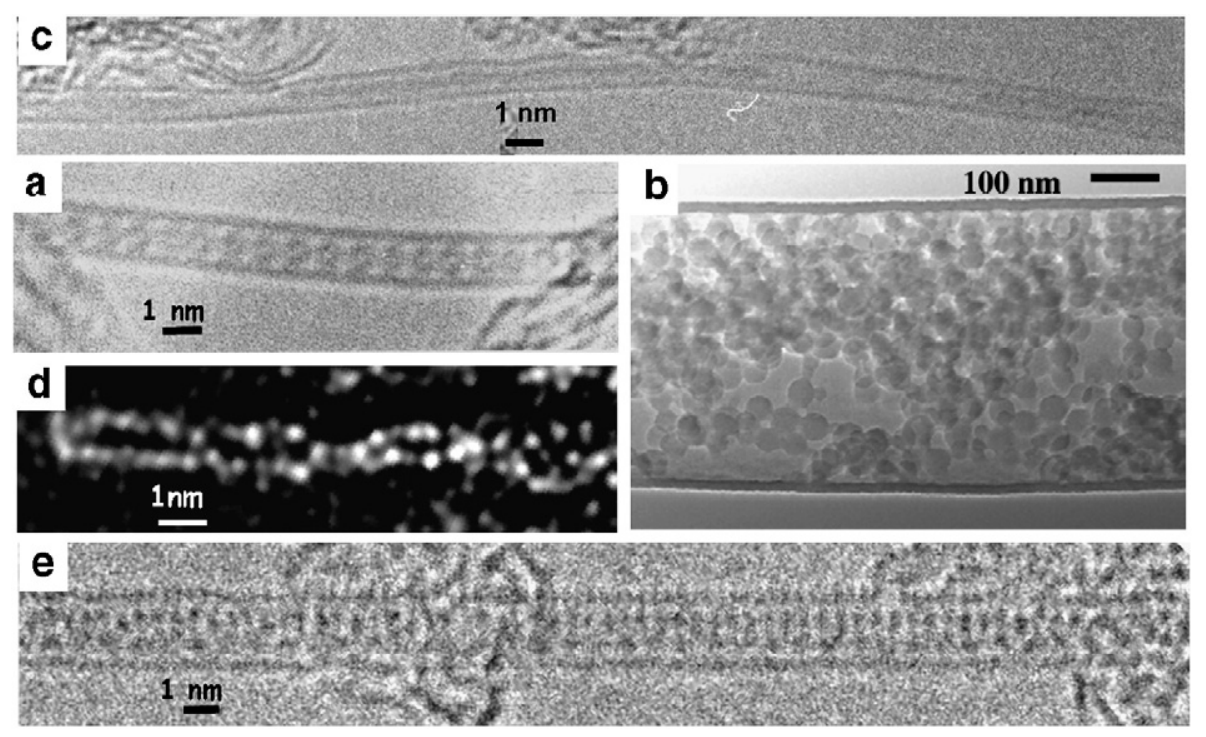

Fig. 2. Examples of transmission electron microscopy (TEM) images of hybrid carbon nanotubes. All are SWNTs, but (b). (a) High resolution TEM image of $\mathrm{C}_{60} @ \mathrm{SWNT}$, so-called nano-peapod, obtained from the gas phase route (two-step procedure). This is the first image ever published, from [6]. (b) TEM image of a large MWNT from templating inserted with polystyrene nanobeads initially suspended in ethylene glycol, as obtained from the suspension method. From [19] by permission of American Chemical Society. (c) TEM image of $\mathrm{CrO}_{\mathrm{x}} @$ aSWNT, obtained from the solution method (single step procedure). From [17]. Sequential filling is shown, as a frequent consequence of the concomitant insertion of solvating molecules, afterwards removed by drying. Sequential (and even periodic) filling is also a frequent feature for encapsulated materials inserted in molten state, as a consequence of volume shrinkage during the liquid to solid transformation [5]. (d) High resolution Zcontrast TEM image of I@SWNT, obtained from the melting method (single step procedure). Only the I atoms are actually seen, displayed as two chains in double helix. From [9], courtesy of E. Dickey, Pennsylvania State University (USA) by permission of American Physical Society. (e) High resolution TEM image of TlCl@SWNT, obtained from the melting method (two-step procedure). From [20].

or clusters whose size is in the range of $1 \mathrm{~nm}$ is not trivial. The counter part is that there is no need for intermediate compounds with such a method. Examples reported so far therefore involve MWNTs only [19,23], in which the suspension viscosity is adjusted by the particle proportion.

The solution method is quite similar to the latter, and consists in putting in contact a concentrated solution of the desired materials with the nanotubes to fill (either SWNTs or MWNTs), in open air or saturated atmosphere, at room or reflux temperature, possibly assisted by sonication (e.g., $[7,16])$. Temperature conditions are therefore quite mild, which allows thermally unstable filling materials such as functionalized fullerenes, biomolecules, etc. For inorganic materials, the method generally requires considering soluble derivatives of the materials wanted to ultimately fill the nanotubes (MWNT or SWNT), such as salts (halides or nitrates, usually). Post-treatments (e.g., calcination, reduction as the most usual, but also others such as photolysis or electron irradiation) are therefore most often necessary to obtain the hybrid nanotube with the desired chemical composition (for instance, as in $[7,16,17]$ ). Supercritical $\mathrm{CO}_{2}$ (requesting high pressures $-\sim 150$ bars, and mild temperatures $-\sim 50^{\circ} \mathrm{C}$ ) may even be used [14] as a valuable alternative to regular solvents (water, acids, chloroform, toluene, etc.) for exhibiting higher solubilization power and lower surface tension. The method can be single step, as in [17], where raw SWNTs were soaked in a saturated solution of $\mathrm{CrO}_{3}$ in $\mathrm{HCl}$. The latter forms $\mathrm{CrO}_{2} \mathrm{Cl}_{2}$ which oxidizes and opens the SWNTs, subsequently allowing the excess $\mathrm{CrO}_{3}$ to enter the nanotube cavity. However, such examples are rare, and most of experiments include two or three steps since requiring the previous opening of the nanotubes and the use of intermediate compounds needing to be subsequently transformed after encapsulation. The main limitation is however that solvent molecules enter the nanotube as well, resulting in preventing high filling rates. Cycling may however partly overcome the problem.

As opposed to the solution method, the melting method allows high filling rates to be achieved, although cumulating filling cycles could be necessary because only the filling material is entering the nanotube cavity. It was first used by Grigorian et al. who tentatively doped SWNTs with iodine [24], and found out 2 years later that iodine actually entered SWNT cavity [9]. It was due to the oxidizing action of molten halides towards polyaromatic carbon which was able to proceed until opening of the SWNTs, as figured out for the first time by Sloan et al. [25]. Although a single step may be enough in favorable cases as in $[9,24]$, the melting method may require three steps, i.e., if the molten material is not oxidizing towards carbon hence making an opening step necessary on the one hand, and in case some post-treatment is needed on the other hand. The latter is actually likely, due to the necessity to deal with materials whose melting temperature is below $1000-1200^{\circ} \mathrm{C}$ (for practical reasons and to prevent damages to the tubes) on the one hand, and whose surface tension at molten state is below $100-200 \mathrm{mN} / \mathrm{m}$ on the other hand. Salts such as halides or nitrates are therefore preferred filling materials. MWNTs are able to be filled with molten materials as demonstrated as early as in 1993 [26], a minimum of two steps is necessary because the oxidizing power of molten materials (e.g., halides) is not sufficient to open the tube wall considering the number of graphenes involved. The single step procedure is therefore limited to SWNTs or DWNTs.

Finally, some original single step methods have been proposed to develop simpler, and/or more efficient, etc., ways to 
synthesize hybrid nanotubes. One proposed to use solutions of halides $\left(\mathrm{FeCl}_{3}, \mathrm{MoCl}_{5}\right.$, I) in chloroform subsequently irradiated with UV at room temperature. Chlorine moieties are thereby created at least from the partial dissociation of $\mathrm{CHCl}_{3}$, which are able to attack the SWNTs, allowing the filling to proceed from the dissolved material. The method, limited to SWNTs for the same reason as above, should be applicable to - but meanwhile is limited to - any compound soluble in chloroform [27,28]. Another method proposed to fill SWNTs from the collision of accelerated atoms (e.g., Cs [29]) or molecules (e.g., fullerenes $[29,30])$ generated from a plasma against SWNTs. Filling rates can be fairly high $\left(\sim 50 \%\right.$ for $\mathrm{C}_{60} @$,SWNTs $)$ with respect to the short duration of the run $(\sim 1 \mathrm{~h})$ which is an advantage with respect to any of the other routes in Fig. 1. However, as for any single step route, whose main feature is that nanotubes are opened in the mean time as they are filled, a main limitation is that only SWNTs can be concerned. Moreover, since opening SWNTs somehow corresponds to SWNT structure degradation, opening and filling events compete, meaning that procedure conditions for obtaining maximum filling rates require to be adequately optimized.

\subsection{Behavior and properties of hybrid nanotubes and filling materials}

Two major examples have been reported of specific behaviors of materials encapsulated in SWNTs. The first one deals with fullerenes, which have shown a series of peculiar behaviors including dimerization, coalescence, and diffusion of the contained molecules. The early observations of the latter behaviors were already reviewed in [8] and will therefore not be detailed here. Related dynamic behaviors upon electron irradiation were also reported for other materials encapsulated in SWNTs such as clusterization of $\mathrm{ZrCl}_{4}$ crystals [31], and steady rotation of $\mathrm{Re}_{x} \mathrm{O}_{y}$ clusters [32].

A second major behavior, which is specific of the encapsulation in SWNTs, is to frequently generate structural discrepancies with respect to the same materials in bulk state. Structural peculiarities actually include preferred orientation with respect to the nanowire elongation axis, reduced coordination, significant anisotropic lattice expansion and/or contraction (up to $14 \%$, and possibly more), and new structures. The latter aspects have been thoroughly reviewed recently in [33,34], whose authors are the main contributors in the field. Although possibly new structure have been suggested for materials inserted in MWNTs [26], discrepancies with structural features in bulk state are certainly limited in MWNTs whose inner space is much larger that for SWNTs, and the latter confinement-induced structural changes are most generally specific to SWNTs.

Besides, the mere fact that encapsulating crystals in SWNTs enforces a nanowire morphology which is generally unusual for most of the filling materials tested so far is a peculiar behavior, as demonstrated by the complete removal of the carbon sheath (formerly regular 1-2-nm-wide SWNTs) which resulted in the lost of this morphology for several halide crystals [35].

If examples of peculiar structures upon nano-encapsulation are many, data making the relation of the latter with some specific properties are still few. Most of reports deal with peapods, because they are easy to prepare and known for long. For instance, the effective charge transfer from the contained fullerenes or metallofullerenes to the encapsulating SWNT was stated, in an extent which is variable according to the SWNT diameter [36,37]. This is consistent with the observation that indirect tunneling between inserted $\mathrm{C}_{60}$ through the SWNT wall is preferred, instead of direct tunneling from $\mathrm{C}_{60}$ to $\mathrm{C}_{60}$ [38-40]. On the other hand, contradictory results have also been reported regarding transport properties since electrical resistivity of $\mathrm{C}_{60} @$ SWNTs (at low temperature) was said to increase [11,41], or decrease [39] with respect to pristine SWNTs. Same for the temperature dependence of Dy@C $\mathrm{C}_{82} @$ SWNT-based field emission transistor characteristics, which was found effective [40] or not [42]. Beside, thermal properties of peapods were found to show no change with respect to pristine SWNTs, presumably because the propagation of phonons from a $\mathrm{C}_{60}$ molecule to the neighboring one is too slow [39].

Some results were however published regarding other hybrid SWNTs than peapods, such as I@SWNT, whose electrical resistivity was found to be significantly decreased with respect to pristine SWNTs, with some evidence for charge transfer [24]. However, in this case, iodine in both doping and filling positions respectively certainly account for this result, without any possibility to estimate the respective contributions. In this regard, modeling will certainly help, either to evaluate the effect of constraining crystal structure, as recently reported regarding the change from semi-metal to semi-conductor of HgTe nanowires upon encapsulation in SWNT [43], or to evaluate the tube/ filling interaction, as reported for $\mathrm{Ag}$ or $\mathrm{CrO}_{3}$ filled SWNTs, whose modeling is confirming the donor or acceptor role of the filling materials respectively towards the containing SWNT in agreement with the resonant Raman data [44].

\section{Conclusions}

Among the various kinds of carbon nanotube derivatives that can be designed and currently prepared, hybrid nanotubes was shown to be probably the most important one for the future development of carbon nanotubes, specifically single-walled. Though progresses and prospects are still necessary regarding synthesis in order to improve filling rates, material variety and quality, and procedures, strong efforts should be made regarding property measurements, theory and modeling. A lot of work is actually still to be made in the latter fields in order to ascertain the possibilities and limitations of hybrid carbon nanotubes. Based on the fact that peculiar behaviors for the encapsulated materials have already been revealed, it is likely that peculiar properties of the whole hybrid nanomaterials (specifically hybrid SWNTs) will be discovered in a close future. To paraphrase well-known Nobel Laureate R. Feynman: There's now plenty of work at the lab.

\section{References}

[1] L.V. Radushkevich, V.M. Lukyanovich, Zurn. Fisic. Chim. 26 (1952) 88. [2] M. Monthioux, V. Kuznetsov, Carbon 44 (2006) 1621. 
[3] S. Ijima, T. Ichihashi, Nature 363 (1993) 603.

[4] D.S. Bethune, C.H. Kiang, M.S. De Vries, G. Gorman, R. Savoy, J. Vasquez, R. Breyers, Nature 363 (1993) 605.

[5] M. Monthioux, E. Flahaut, J.-P. Cleuziou, J. Mater. Res. (in press).

[6] B.W. Smith, M. Monthioux, D.E. Luzzi, Nature 296 (1998) 323.

[7] J. Sloan, J. Hammer, M. Zwiefka-Sibley, M.L.H. Green, Chem. Commun. (1998) 347.

[8] M. Monthioux, Carbon 40 (2002) 1809.

[9] X. Fan, E.C. Dickey, P.C. Eklund, K.A. Williams, L. Grigorian, R. Buczko, S.T. Pantelides, S.J. Pennycook, Phys. Rev. Lett. 84 (2000) 4621.

[10] B.W. Smith, D.E. Luzzi, Y. Achiba, Chem. Phys. Lett. 331 (2000) 137.

[11] K. Hirahara, K. Suenaga, S. Bandow, H. Kato, T. Okazaki, H. Shinohara, S. Iijima, Phys. Rev. Lett. 85 (2000) 5384.

[12] K. Suenaga, M. Tence, C. Mory, C. Colliex, H. Kato, T. Okazaki, H. Shinohara, K. Hirahara, S. Bandow, S. Iijima, Science 290 (2000) 2280.

[13] T. Pichler, A. Kukovecz, H. Kuzmany, H. Kataura, Y. Achiba, Phys. Rev., B 67 (2003) 125416.

[14] D.A. Britz, A.N. Khlobystov, J. Wang, A.S. O’Neil, M. Poliakoff, A. Ardavan, G.A.D. Briggs, Chem. Commun. (2004) 176.

[15] D.E. Luzzi, B.W. Smith, R. Russo, B.C. Satishkumar, F. Stercel, N. Nemes, Am. Inst. Phys Conf. Proc. Series, vol. 591, 2001, p. 622.

[16] C.H. Kiang, J.S. Choi, T.T. Tran, A.D. Bacher, J. Phys. Chem., B 103 (1999) 7449.

[17] J. Mittal, M. Monthioux, H. Allouche, O. Stephan, Chem. Phys. Lett. 339 (2001) 311.

[18] S. Friedrichs, R.R. Meyer, J. Sloan, A.I. Kirkland, John L. Hutchison, M.L.H. Green, Chem. Commun. (2001) 929.

[19] B.M. Kim, S. Qian, H.H. Bau, Nanoletters 5 (2005) 873.

[20] E. Flahaut, J. Sloan, K.S. Coleman, V.C. Williams, S. Friedrichs, N. Hanson, M.L.H. Green, Mater. Res. Soc. Symp., A 633 (2001) A13.15-1.

[21] B.W. Smith, D.E. Luzzi, Chem. Phys. Lett. 321 (2000) 169.

[22] E. Dujardin, T.W. Ebbesen, H. Hiura, K. Taginaki, Science 26 (1994) 1850 .

[23] G. Korneva, H. Ye, Y. Gogotsi, D. Halverson, G. Friedman, J.-C. Bradley, K.G. Kornev, Nanoletters 5 (2005) 879.

[24] L. Grigorian, K.A. Williams, S. Fang, G.U. Sumanasekera, A.L. Loper, E.C. Dickey, S.J. Pennycook, P.C. Eklund, Phys. Rev. Lett. 80 (1998) 5560.

[25] J. Sloan, D.M. Wright, H.G. Woo, S. Bailey, G. Brown, A.P.E. York, K.S. Coleman, J.L. Hutchison, M.L.H. Green, Chem. Commun. (1999) 699.

[26] P.M. Ajayan, S. lijima, Nature 361 (1993) 333.
[27] J. Mittal, M. Monthioux, H. Allouche, Proc. 25th Biennial Conf. on Carbon, University of Kentucky, Lexington, USA, 2001, CD-Rom, Novel/14.2.

[28] J. Mittal, M. Monthioux, V. Serin, J.-P. Cleuziou, Chinese-French Workshop on Carbon Materials, 2005, Groupe Français pour l'Etude du Carbone, Orléans (France), 2005.

[29] G.-H. Jeong, R. Hatakeyama, T. Hirata, K. Tohji, K. Motomiya, T. Yaguchi, Y. Kawazoe, Chem. Commun. (2003) 152.

[30] G.-H. Jeong, R. Hatakeyama, T. Hirata, K. Tohji, K. Motomiya, N. Sato, Y. Kawazoe, Appl. Phys. Lett. 79 (2001) 4213.

[31] G. Brown, S.R. Bailey, J. Sloan, C. Xu, S. Friedrichs, E. Flahaut, K.S. Coleman, J.L. Hutchison, R.E. Dunin-Borkowski, M.L.H. Green, Chem. Commun. (2001) 845.

[32] P.M.F.J. Costa, J. Sloan, T. Rutherford, M.L.H. Green, Chem. Mater. 17 (2005) 6579.

[33] J. Sloan, A.I. Kirkland, J.L. Hutchison, M.L.H. Green, Chem. Commun. (2002) 1319.

[34] J. Sloan, A.I. Kirkland, J.L. Hutchison, M.L.H. Green, C.R. Phys. 4 (2003) 1063 .

[35] J.S. Bendall, A. Ilie, M.E. Welland, J. Sloan, M.L.H. Green, J. Phys. Chem. 110 (2006) 6569.

[36] Y. Cho, S. Han, G. Kim, H. Lee, J. Ihm, Phys. Rev. Lett. 90 (2003) 106402.

[37] A. Rochefort, Phys. Rev., B 67 (2003) 115401.

[38] D.J. Hornbaker, S.-J. Kahng, S. Misra, B.W. Smith, A.T. Johnson, E.J. Mele, D.E. Luzzi, A. Yazdani, Science 295 (2002) 828.

[39] J. Vavro, M.C. Llaguno, B.C. Satishkumar, D.E. Luzzi, J.E. Fischer, Appl. Phys. Lett. 80 (2002) 1450.

[40] T. Shimada, Y. Ohno, T. Okazaki, T. Sugai, K. Suenaga, S. Kishimoto, T. Mizutani, T. Inouea, R. Taniguchi, N. Fukui, H. Okubo, H. Shinohara, Phys., E 21 (2004) 1089.

[41] H. Hongo, F. Nihey, M. Yudasaka, T. Ichihashi, S. Iijima, Phys., B 323 (2002) 244.

[42] P.W. Chiu, S.F. Yang, S.H. Yang, G. Gu, S. Roth, Appl. Phys., A 76 (2003) 463.

[43] R. Carter, J. Sloan, A.I. Kirkland, R.R. Meyer, P.J.D. Lindan, G. Lin, M.L.H. Green, A. Vlandas, J.L. Hutchison, J. Harding, Phys. Rev. Lett. 96 (2006) 215501.

[44] S.B. Fagan, A.G. Souza Filho, J. Mendes Filho, P. Corio, M.S. Dresselhaus, Chem. Phys. Lett. 406 (2005) 54. 